POLICY PERSPECTIVES

\title{
Agriculture at a Crossroads
}

\section{Ensuring Conservation and Income Support in the Farm Bill}

\section{By Amy Fredregill}

Abstract: While most farmers take steps to enhance natural resources, times of low prices and high costs may create difficulties for farmers who wish to spend resources on agriculture conservation. Consequently, farming can have a harmful effect on natural resources. Because many farmers rely on income support payments, and most income programs do not require farmers to utilize environmental conservation practices, environmental degradation continues. To ensure adequate protection of water quality, soil quality and wildlife habitat, and to provide income support for farms of all sizes, politically feasible legislation is needed to link income payments with conservation practices. This article follows the outline of a traditional policy analysis to examine four policy options for the farm bill: the Conservation Security Program (CSP), Flex Fallow, the Conservation Reserve Program, and conservation easements. The options range from conservative to liberal, with differing environmental and income impacts. Policy options for achieving these goals were judged using the following criteria: effectiveness in achieving conservation goals; effectiveness in supporting farmer income; political feasibility; and strength of the linkage between conservation practices and income payments. Based on this analysis, CSP is the best option for the farm bill, because it is a compromise approach to achieving the goals of this analysis.

This evaluation is presented as a policy analysis in order to provide a systematic technique for identifying solutions to current farm policy problems. The elements of a policy analysis traditionally include formulating a problem, identifying policy alternatives, forecasting the future, modeling the impacts of alternatives, and comparing and ranking the policy alternatives.

\section{What's Happening Out in the Fields?}

Nearly 70 percent of the land in the contiguous 48 states is held in private ownership, and 50 percent of this property is managed as cropland, pastureland, or rangeland. Nine hundred million acres of land, or 41 percent of the continental United States, is used for agricultural production (USDA, 1997). The practices used by farmers on this vast amount of land determine the health of natural resources found there.

There is a strong link between productive agriculture and the conservation of soils, the abundance of wildlife and the quality of water supplies in an area. While most farmers maintain practices to enhance natural resources, times of low prices and high costs make it difficult for farmers to personally finance agriculture conservation,

For these reasons, agriculture can contribute to environmental problems such as water quality degradation, soil erosion and sedimentation, loss of wetlands, and a decline in wildlife habitat. A study conducted by the Commission on $21^{\text {st }}$ Century Production Agriculture reports on many of these trends (1998). Approximately 30 percent of all cropland acres are eroding at a rate greater than the $\mathrm{T}$ value, which is the tolerable level of erosion believed to be acceptable to maintain soil productivity. Total soil loss on all cropland fell by 42 percent between 1982 and 1997, but soil loss remains far above the acceptable level.

Decreasing the rate of erosion is important because reduced erosion rates are widely thought to contribute directly to maintaining a productive cropland base (Commission on $21^{\text {st }}$ Century Production Agriculture, 1998). In addition, one of the major threats to water quality from agriculture is sediment, often with nutrients or chemicals attached to soil particles, that enters streams and rivers as a result of soil erosion.

Water resources are affected in this and many other ways by agricultural production. Agricultural activities may introduce siltation, nutrients, pesticides, and organic matter that deplete oxygen in surface water. In the 1998 National Water Quality Inventory, agriculture was identified as the leading source of impairment in the nation's rivers, affecting 60 percent of the impaired rivers and streams and 30 percent of the impaired lakes (EPA,

Amy Fredregill earned a Master s of Public Policy degree, with a concentration in environmental policy, from The George Washington University School of Business and Public Management. Ms. Fredregill currently works for the majority staff of the Senate Agriculture Committee. Prior to joining the Committee staff, she served as a program coordinator for the Izaak Walton League of America, Ms. Fredregill holds a bachelors of Arts in Economics from the College of St. Benedict in St. Joseph, MN. 
2000). In addition to the surface water, pesticides and nutrients can leach into and contaminate groundwater, a major source of drinking water. Furthermore, agriculture is the largest consumer of water, using 85 percent of all the water that is consumed in the United States.

Fish and wildlife are also greatly affected by agriculture. Seventy percent of wildlife depends on agricultural land for food and shelter (WMI, 2002). The distribution and abundance of fish and wildlife populations have been substantially affected by agriculture (Hohman, 2000). Loss of biodiversity and declines in wildlife populations during the past century are challenges for continuing land stewardship.

The environmental challenges faced by farmers are exacerbated by the difficult economic circumstances many of them are enduring. Corn, wheat, and soybean prices are at historic lows (Johnson, 2000). Despite substantial subsidies, the number of farms in the United States has declined by more than two-thirds in the last 50 years. Today, only about 150,000 farmers produce most of the food in America (USDA, 2001).

These disturbing trends continue despite surplus U.S. farm production for more than a century. Abundant world supplies and declining export demand have kept prices for most U.S. farm commodities (and, thus, farm income) quite low.

\section{Challenges: Environmental Degradation and Low Farm Income}

Farmers generally do not have incentives to invest in adequate conservation practices. As a result, agricultural production can negatively affect natural resources. Support is needed to help farmers and ranchers maintain and adopt conservation practices on their land.

The primary challenges that current farm policy must consider are:

- Poor agricultural conservation practices;

- Low farmer income; and

- Weak links between farm income payments and conservation practices.

Compliance with particular conservation measures is a requirement for participation in some existing farm income support programs; this stipulation is known as conservation compliance. Some government income support payments, however, do promote the cropping of environmentally sensitive lands that would be difficult to farm otherwise. Other farmers do not receive funds to practice conservation because they are not eligible for either traditional conservation programs or for income support programs that would require conservation compliance. As a result, the reality is that money, such as crop insurance and disaster payments, largely determines what happens on private farmland. As evidenced by Figure 1, conservation received only 16 percent of total farm program spending between Fiscal Year (FY) 1996 and FY 2002. Of the 13 billion dollars spent on farm programs, only 2 billion dollars went to conservation. In contrast, the commodities programs received just under 9 billion dollars (CRS, 2001).

\section{Figure 1: Total Farm Program Spending: FY96-02}

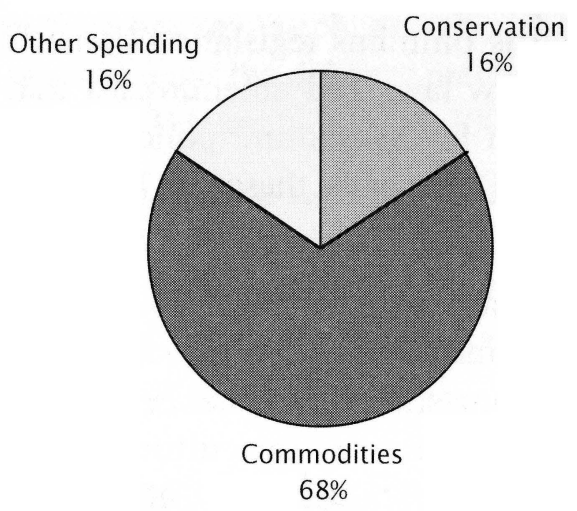

Source: CRS, 2001

A transition to a program where payments are based on conservation goals would alter the current distribution of payments based on production. To make this change, farmers need to be encouraged to implement sustainable practices central to their production processes. Good conservation incentive programs will help them do this while they make money.

One solution is to focus on programs for conservation on working lands. Figure 2, however, demonstrates that current funding for conservation programs focuses instead on land retirement programs; 89 percent, or 1.6 billion dollars of the 1.8 billion dollars of mandatory funds is spent on land retirement programs (Committee on Agriculture, 2001). Some of these funds could be shifted towards land in production to help address the problems identified here. 
Figure 2: Mandatory Conservation Program Funding

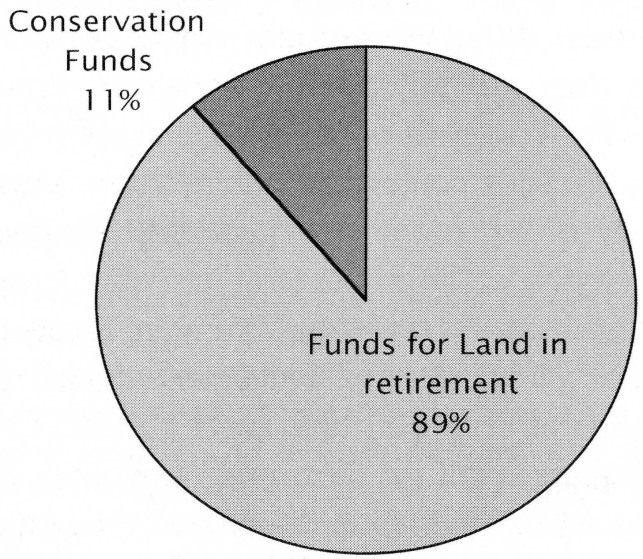

Source: Committee on Agriculture, U.S. Senate, 2001

\section{The History of Farm Policy}

A farm bill is omnibus legislation consisting of a collection of new laws and amendments that set the overall direction for agriculture policy over multiple years (CRS, 2001). Recently, these bills have been passed every five to six years.

Many different titles, or sections, comprise the larger farm bill. These include trade, foreign food aid, forestry, conservation, domestic food assistance (including Food Stamps), crop insurance, agricultural credit, rural development, agricultural research, and others. Because of the wide variety of issues covered in farm bill titles, they affect much more than just farming and farmers.

This analysis focuses on the conservation title, but commodity programs - the price and income support programs - historically are the centerpiece of each farm bill. Farm bills establish farm income and commodity price support policy that the federal government uses to provide support to agricultural producers. Income support programs make payments to agriculture producers to supplement their earnings without directly supporting commodity market prices. "This type of support includes: (1) production flexibility contract (PFC) payments to wheat, feedgrain, cotton, and rice farmers; (2) loan deficiency payments for contract crops and oilseeds when market prices are lower than loan rates; (3) disaster relief payments; and (4) in recent years, ad hoc emergency market loss payments" (CRS, 2001). In addition, commodity price support programs directly affect commodity prices by establishing minimum prices.
Conservation could be defined as the management of human and natural resources to provide maximum benefits over a sustained period of time. In farming, conservation entails matching cropping patterns and the productive potential and physical limitations of agricultural lands to ensure long-term sustainability of profitable production (CRS, 1997). Conservation practices focus on conserving soil, water, energy, and biological resources.

Congress first created conservation programs in the late 1930s to respond to dust bowl conditions. After World War II, programs focused on increasing farm production by providing water to agriculture (CRS, 2001). In the early and mid-1970s, the prices of farm commodities rose significantly, due to diminished stocks and increased export demand. U.S. producers responded by planting on marginal cropland and on range and pasture lands. Excessive rates of erosion, rivaling those of the 1930s dust bowl, were one by-product of this expansion. This activity continued until the early 1980s, when overproduction and a strengthening U.S. dollar depressed prices, causing farm income to fall to its lowest level since the Depression. Producers were left with excess capacity and shrinking markets.

Meanwhile, public concern began to grow over the damage caused by agricultural erosion and water runoff carrying sediment, nutrients, and chemicals into streams, rivers, lakes, and other bodies of water. The U.S. Department of Agriculture (USDA) released studies reporting that the nation's cropland was eroding and suffering soil losses at a rate exceeding 3 billion tons per year. Intensive farming and the conversion of idle land into production also had destroyed habitats for many species, leading to declining wildlife populations (Farm Service Agency, 1999).

For the first 50 years of federal conservation programs, through the mid-1980's, programs focused almost exclusively on soil erosion, water supply, and flood control; the goal of these efforts was to enhance farm productivity. Federal programs allowed farmers to receive payments for acres not planted, referred to as annual set asides, but did not include any multi-year efforts that could provide more enduring benefits for either conservation or the producer's bottom line (Farm Service Agency, 2000). Since 1985, congressional farm bill conservation goals have expanded to address water pollution, wetland protection, wildlife enhancement, and improved air quality. 
In 1985 Congress passed the Food Security Act to address oversupply, low income, and soil erosion; the Conservation Reserve Program (CRP) was one of the new initiatives in the bill. The 1990 farm bill moved agriculture toward a market orientation by freezing target prices and allowing more planting flexibility, but it also reduced the acreage to be enrolled in CRP.

The 1996 farm bill, the FAIR Act, widely known as Freedom to Farm, focused on commodity interests. The budget captured for agriculture was primarily designated for commodity programs; the interests of conservation, rural development, and other activities were secondary (Doering, 2000). FAIR removed the link between income support payments and farm prices. It authorized 7-year production flexibility contract payments that provide producers with fixed government payments independent of current farm prices and production. FAIR also established the Agricultural Market Transition Act (AMTA). Under this title, some 36 billion dollars in AMTA payments are to be made to farmers for contract crops for fiscal years 1996-2002. A farmer's payment is based on a percent of a farm's contract acreage. FAIR sets payment limits at $\$ 40,000$ per person per fiscal year on production flexibility contracts. Farmers do not need to use conservation practices to obtain payment.

Currently, USDA administers several conservation programs through both the Natural Resources Conservation Service and the Farm Service Agency. These agencies provide producers opportunities to manage their privately owned agricultural lands in a manner that enhances natural resources. USDA programs in the conservation title of the farm bill include the CRP, Wetlands Reserve (WRP), the Environmental Quality Incentives Program (EQIP), the Farmland Protection Program (FPP) and the Wildlife Habitat Improvement Program (WHIP). Conservation program implementation has contributed to the objectives of soil, water, and wildlife enhancement on private lands. These voluntary conservation programs proved so popular that in 2001, WRP, FPP, and WHIP depleted their funding or reached their acreage limit (Committee on Agriculture, 2001).

Despite the popularity of some of its programs, FAIR has not provided the type of flexible and marketresponsive income protection needed by farmers in the current economy. When legislation was enacted, the farm sector enjoyed high prices and an expansion of exports; these conditions were expected to continue. With exports falling in late 1997 due to the Asian financial crisis and good growing seasons in major producing regions, commodity prices fell by 50 percent or more from their 1996 peaks.

Lower prices and reduced federal support payments in the late 1990s created new difficulties for U.S. farmers. Congress responded to these bad times by passing emergency agriculture aid bills, providing emergency supplemental farm assistance totaling more than 30 billion dollars over four consecutive years (Committee on Agriculture, 2001). There has been little debate over the need for additional farm income assistance or whether underlying farm policies are adequate. Disagreements revolve around the design of the assistance program, such as who should receive payments, and what the delivery mechanism should be (Congressional Research Service, 2000B).

The 1996 bill is set to expire on December 31, 2002. At that time, a number of programs, including commodity supports, will expire and the authority under these provisions will either revert to earlier, permanent law, or will terminate (CRS, 2001).

\section{So What Should the Priorities Be?}

A main priority for the next farm bill should be to ensure long-term sustainability of soil resources, water resources, and wildlife habitat. These goals should be accomplished through politically feasible policies that will strengthen stewardship by those who make their living from the land without threatening their livelihood in the process.

Policies in the next farm bill should meet the following goals:

1. Increase environmental conservation for water, soil, and wildlife habitat

2. Increase farm income in an equitable way for all farms

3. Increase the link between income support payments and conservation practices.

Farm bill programs by themselves will not solve all the natural resource problems in this nation, but they can provide an essential vehicle to address land-related problems in a consistent manner. To address agriculture's negative externalities, compensation for conservation could go far in achieving sustainability of 
natural resources. If agriculture income programs are based on conservation, the obligations farmers must meet become a key question for the justification of payments. These payments could be directed to producers who have implemented and maintained a comprehensive land care plan. In a recent report, USDA noted that "the current imbalance favoring land retirement suggests an untapped potential for achieving cost-effective environmental benefits from conservation spending on working lands. Further, many emerging agri-environmental problems can be addressed only by changing management practices on working land" $(2001,10)$.

It is also important to stress the goal of political feasibility. Advocating for a politically infeasible policy would be a disservice to environmental protection. A bill that does not get passed because it is politically infeasible, even if it is the ideal bill, will not achieve any conservation goals. Instead, a compromise approach that has a high chance of acceptance can produce real incremental environmental improvements.

As a side note, conservation and income support may seem to be counter-intuitive goals. The goal, however, is not to simply increase income by increasing production; instead, the goal is to alter the current income support programs to reward conservation practices on land both in retirement and in production.

\section{The Political Climate}

Farm bills tend to be reactive, responding to events and trends in the agriculture industry in the years preceding the bill. Farm bill negotiations are very much influenced by groups whose goal it is to enhance incomes of farmers and landowners; this is especially important today for these groups given the current backdrop of low prices. Environmental groups have less influence on these political negotiations, in part because some legislators do not believe that there are major problems in the current legislation. Conservation goals will be addressed to a certain extent in legislation, but most likely through politically appealing programs that have a dual role of enhancing incomes of farmers and providing for conservation.

Due to budgetary concerns and the strength of commodity interests, new conservation programs are difficult to approve. In this era of political moderation, legislation with radical changes to farm programs will not be popular. Most current Members of Congress have shown a preference for making minor changes to current programs instead of creating new programs that will require new funding. Incremental approaches will probably be more successful, as is usually the case in politics. Given the close partisan split in both the House and Senate, any proposed program must be favorable both to conservative and liberal members of Congress if it is to pass.

Despite the "go-slow" approach in Congress, over the years the variety of issues covered by farm bills has made possible many broad coalitions of support among common and diverse interests. These sometimes unusual partnerships have allowed for the creation of policies and programs that otherwise might not have been enacted.

An interesting question in this debate is the relevance of the issues involved and whether the public has articulated goals for farm programs (or if it even has an interest in doing so). In the absence of a well-voiced public consensus, many commodity and agribusiness concerns have the ability to influence political resources in a democratic system and gain access to key decisionmakers, thereby affecting policy and budgetary priorities. This political fact of life has allowed some agriculture interests to obtain what may be considered by some to be disproportionate resources (Doering, 2000).

\section{Criteria}

For the farm bill, policy alternatives should be evaluated on the basis of several factors. The following criteria are suggested as practical guidelines for discussing various policy alternatives:

\section{Effectiveness in Conservation}

Water and soil quality: This criterion evaluates the effectiveness of conservation in water and soil quality based on the type of farming practices encouraged and their estimated environmental impact. Changes in soil erosion and sedimentation, chemical and nutrient runoff, and water quality impairment will be evaluated. In this analysis, an alternative will be rated highest if the land is retired because of the resulting environmental improvements from halting production on the land.

Wildlife habitat: This criterion evaluates the extent to which the alternative would improve wildlife habitat. 
It will be measured by whether the program allows land to be left idle, and whether it increases wildlife-friendly groundcover-a crop planted to prevent soil erosionsuch as providing for increased groundcover for land for longer time periods.

Effectiveness in increasing income equitability: This criterion will evaluate the likelihood that the alternative will help improve the income of farmers. Effectiveness will be measured by the flexibility of the program for providing income, and whether a cap is placed on the program or if all farmers who are eligible can receive payments.

\section{Feasibility}

Political feasibility: This criterion will evaluate whether the policy is likely to be approved by Congress and the president. Feasibility will be measured by the number and variety of co-sponsors, including bi-partisan support, and if the policy alternative has interest group support in different regions. An alternative that meets the political feasibility criterion will ideally achieve an acceptable middle ground between opposing views.

Administrative feasibility: This criterion will be measured by whether a policy option would create new programs or bureaucracies.

Links between income and conservation: This criterion will measure the degree to which the program prescribes requirements linking income payments to conservation practices, focusing on the strictness of requirements and adequacy of enforcement. The evaluation will focus on whether increased conservation practices trigger higher income payments. A lack of this type of incentive will lead to a lower score.

Cost is not included as a separate criterion. Cost inherently affects feasibility, so the impact of cost is reflected in the degree of political support and feasibility of the alternative. The reality, however, is that conservation programs are often not fully funded and that cost can then become a major concern.

The voluntary nature of the programs being evaluated increases the difficulty of evaluating their impact. It is difficult to estimate effects of incentives on farmers who are characteristically independent and traditional. Farmers do not easily change their ways.

In addition, the uncertainty of the market also makes it difficult to anticipate farmers' actions. Farmers base many of their decisions on national and global commodity prices and forecasts. These prices affect their farming decisions, including conservation practices. Changes in the farm economy could greatly influence the projections made for the impacts of the policies in this analysis.

\section{Alternative Policy Options}

Several policy alternatives have been identified as possible solutions to the identified problems. The alternatives considered here are all voluntary programs, designed to be only one part of a larger farm bill. These policies are complementary (in a policy analysis, the term 'alternatives' does not necessarily mean that the options are mutually exclusive) (Bardach, 2000) and would never solely comprise the conservation title of a farm bill. Instead, these types of policy options would be part of a larger package.

The options for conservation programs range from conservative to liberal, with differing environmental and income impacts. The Conservation Reserve Program (CRP), a land-retirement program begun in 1985 , is the status quo option. Flex Fallow is the most conservative approach, focusing mainly on providing flexibility and income support, compared to CSP which allows land to remain in production but requires farmers to achieve certain environmental requirements in order to receive payments. A conservation easement program is the most liberal approach, taking land completely out of production for a period of 10 to 15 years, and focusing on environmental benefits.

Based on the following analysis, CSP, a compromise approach that focuses on conservation on productive agriculture lands, appears to be the best option. CSP meets the needs of current agricultural policy, especially the goal of ensuring conservation.

\section{CRP: The Status Quo Approach}

$\mathrm{CRP}$ is the nation's largest environmental program, created to retire from production up to 45 million acres of highly erodible and environmentally sensitive farmland. A voluntary long-term cropland retirement program, CRP provides participants with an annual peracre rent plus half the cost of establishing a permanent land cover (usually grass, bushes or trees). In exchange, the participant retires highly erodible or environmentally sensitive cropland from production for 10 to 15 years, 
The program is currently capped at 36.4 million acres, its 1995 level; due to CRP's popularity, this acreage limit in most years is nearly met. In the spring of 2001 more than 33,596,000 acres were enrolled in CRP. Some stakeholders support raising the cap on $\mathrm{CRP}$, while others support allowing shorter contracts. For this analysis, the program is assumed to remain at its current level-36.4 million acres-as the status quo option. CRP would be part of a baseline conservation title, in addition to other existing conservation programs such as WRP and EQIP, if no new conservation provisions were added to the farm bill. This approach is somewhere between middle-of-the-road and conservative on the spectrum of options.

Effectiveness in conservation: Much of the decline in soil erosion rates over the last decade can be attributed to implementation of the CRP and the widespread adoption of conservation tillage practices that help reduce erosion (Commission on $21^{\text {st }}$ Century Production Agriculture, 1998). CRP, however, is limited by the acreage cap established by statute. This limitation obviously reduces the number and type of farmers who can enroll in the program, thereby limiting environmental benefits.

According to the Natural Resources Conservation Service (NRCS), each acre under CRP contract reduces erosion by an average of 19 tons of topsoil a year. CRP has reduced 694,062,336 total tons per year in erosion reduction (Farm Service Agency, 1997). While the number of enrolled CRP acres has remained constant, the erosion rate on CRP acres has declined from 9.4 tons per acre per year in 1987 to 0.8 tons per acre per year in 1997-a 91.5 percent reduction (Uri, 2001). This in turn improves the quality of water in streams, lakes, and other water bodies by reducing sediment, nutrients, and pesticides.

CRP was ranked to have medium to high water and soil benefits. The land does not remain in production as it does under CSP, so this alternative is estimated to have fewer benefits than conservation easements. In addition, USDA estimates CRP results in 2 billion dollars in enhanced uses of wildlife since retired CRP land provides very good habitat for wildlife.

Effectiveness in increasing income: Supporters of CRP believe the program could help farmers by removing land from production while providing stable income. USDA economists estimate that CRP increases net farm income by 5.1 billion dollars per year (FSA, 1999). Thirteen percent of farms participate in CRP, representing 293,857 farmers (WMI, 2002). Although CRP provides billions annually in net farm income, it received a medium rating because the funding for $C R P$ is capped annually. This limits the number of farmers who can benefit from the program compared to CSP and Flex Fallow which are not capped.

Links between income and conservation: The strength of the conservation requirements for CRP are moderate; the impact would be greater if the program were not capped and if it were not as flexible. The conservation requirements for what must be done with the retired land are not very strict.

Feasibility: CRP has substantial support as one of the country's most successful environmental programs. But if it were the sole option for conservation in the farm bill, CRP would likely receive only moderate support because many groups feel that more changes are needed to the current conservation programs and that relying only on a baseline of CRP will not fully achieve environmental goals. Another perspective is from mainstream farm organizations who are concerned that if too many acres are enrolled in CRP the large amount of land that is thereby taken out of production will lead to reduced farm-related income for business and industry in rural communities. In terms of regional equity, some organizations are also concerned that CRP often benefits recipients in the Plains and Northern Plains more than any other region. At the same time, a perceived advantage for $\mathrm{CRP}$ is that its evaluation for administrative feasibility is high because the current mechanisms for administering the program are in place.

\section{Conservation Security Program: The Compromise}

The Conservation Security Program (CSP), a centerpiece of the Senate farm bill that was initially proposed by Tom Harkin (D-Iowa), emphasizes sustainable management of productive farmland as an alternative to land retirement and payments for production of commodity crops. CSP is a complement to the safety net provided by current commodity payment programs and also to current conservation programs.

CSP would establish a system in which any farmer with land in production could enter into contracts with the USDA and choose from one of three "conservation 
classes" to receive income for maintaining or adopting conservation practices. Payment criteria under CSP are based in part on the extent to which the adopted conservation practices maximize environmental benefits and the cost of implementation and foregone profit, if any, resulting from the adoption of conservation practices. The legislation sets the top level of payments at $\$ 50,000$ maximum per farm operator under 5- to 10 year contracts with the government. Annual payments may be up to $\$ 20,000$ for basic land management and conservation practices, up to $\$ 35,000$ for land use practices including resource-conserving crop rotations, and up to $\$ 50,000$ for adoption of a whole-farm approach that focuses on the long-term sustainability of the natural resource base.

This is the compromise approach between supporting conservation and income. Whereas CRP retires land, CSP works with land in production.

Effectiveness in conservation: CSP is given a medium ranking for this criterion because it may result in fewer environmental benefits due to less land being left idle than if the land was in CRP or conservation easements. The program also has shorter contracts than preferred by many environmentalists who prefer longer contracts that enhance wildlife habitat. CSP's shorter contracts do not result in as many environmental benefits but are more beneficial to wildlife than Flex Fallow.

At the same time, because more farmers may be eligible for the program than are eligible for CRP, the cumulative environmental benefits may be greater than CRP. CSP would result in more conservation practices than Flex Fallow because of its prescribed requirements for receiving payment which should result in reduced erosion, sedimentation, and chemical and nutrient runoff. CSP scores a medium for this criterion because of the estimated cumulative wildlife effects of the program.

Effectiveness in increasing income: CSP is evaluated to have a high impact on improving farmer income because of the flexibility of the program. All who qualify to participate in the program will be able to do so without limitations on the number of acres or available funding, unlike CRP and other programs for which the total number of enrolled acreage is capped and farmer demand exceeds available funding. The cap at $\$ 50,000$ keeps large farms from receiving a disproportionately greater amount of money.

Links between income and conservation: The detailed payment requirements link funding to conservation practices. Depending on the farmer's "conservation class," requirements range from strict to flexible. Increased payments are triggered by more advanced and comprehensive conservation practices; therefore, CSP scores the highest mark for this criterion.

Feasibility: CSP does have broad-based support, demonstrated by its bi-partisan co-sponsors. In addition, many groups currently support the idea from a broad spectrum - family farmers, farmers union, conservation organizations-compared to other alternatives that have less public support. Thus, CSP is the most feasible option. CSP, however, may result in the most complicated administrative delivery of all the options. The tiers of conservation classification structure for CSP may create complicated applications and new levels of bureaucracy.

\section{Flex Fallow: The Conservative Approach}

In January 2001 Senator Tim Johnson (D-South Dakota) introduced the Food Security and Land Stewardship Act of 2001 (S.130) creating a new program, Flex Fallow. (Cultivated land allowed to lie idle during the growing season is referred to as fallow). This innovative program would enable producers to grow crops on their most productive land and idle the least productive and environmentally sensitive portion of their total planted acreage - up to 30 percent of their total acreage. In exchange, the farmer receives more attractive loan rates for marketing assistance loans on the remaining acreage, which is an incentive to put more land into annual set-asides. Very few requirements exist for what must be done with this idled land.

The program is market-oriented, supports full agricultural production, and is designed to allow producers to resume their role as price-setters who respond to the free market (Johnson, 2000). Consequently, Flex Fallow would represent a more conservative approach compared to the other alternatives based on its focus on crop production. This option would likely result in more income but less conservation.

Effectiveness in conservation: Flex Fallow attempts to be effective at conservation by providing better loan 
rates as incentives for idling land for year-long periods. Also, Flex Fallow would take marginal land out of production. The program receives a low rating, however, because it prescribes very few conservation requirements for the land put in set-aside. But even though the contracts are short, they should result in some short-term reduction in soil erosion, chemical runoff, and sedimentation.

In addition, Flex Fallow receives the lowest rating for wildlife benefits. The benefits would be less than that achieved by CSP because contracts are shorter but could result in some increased wildlife habitat because some wetlands will be set aside,

Effectiveness in increasing income: Because land can remain in production, farmers might be more inclined to sign up for Flex Fallow contracts than some of the other programs. The flexibility of the program provides a high level of income support and therefore provides a surer income safety net than $\mathrm{CRP}$. A recent Food and Agriculture Policy Resources Institute (FAPRI) study shows that for the agricultural sector as a whole, total farm income increases with Flex Fallow. Between 2000 and 2008, net farm income is projected to average 51.7 billion dollars with Flex Fallow as compared to 46.9 billion dollars under the baseline scenario (FAPRI, 1999). The benefits may accrue evenly between different sized farms but the program may not be attractive in Farm Belt states because of higher land values there.

Links between income and conservation: Flex Fallow demands nominal requirements for receiving payments. Farmers must take land out of production to receive the program's better loan rates. At the same time, few long-term requirements exist because land can be put back into production the following year. Few conservationists consider this program to be very effective in achieving environmental goals because contracts are established only on an annual basis. Also, farmers cannot receive the better loan rates on the other 70 percent of their land even if it is also put into setasides.

Feasibility: The bulk of support for Flex Fallow comes from farmers, not conservationists, because of the flexibility of the program. Instead, conservationists prefer CSP because it prescribes more requirements for the participating farms. The sponsor of Flex Fallow feels that it is complementary to CSP and that the two programs could be combined. The agriculture industry prefers the shorter contracts offered by Flex Fallow which allow farmers to farm 100 percent of their land in years that are deemed financially beneficial. Little support for Flex Fallow is evident outside of the commodity interests in the agriculture industry, possibly due to the low visibility of the program.

\section{Conservation Easements}

Conservation easements are the acquisition of rights and interest to a property to protect environmentally sensitive lands or to reduce land and water degradation. Since the mid-1970s, conservation easements have protected nearly 420,000 acres of farmland in 15 states, primarily in the Northeast (Congressional Research Service, 1997). The goals of a new conservation. easement program would be to protect targeted wildlife, water quality, and open space while providing for continued economic use by the owners who must implement a conservation management plan.

The 1996 Farm Bill deleted an environmental easement program that had been authorized in 1990 but not implemented. It was designed to work in a similar manner to the Wetlands Reserve Program but with broader protections and increased emphasis on allowing compatible uses of the land; a new easement program would follow this type of outline. Proposed grassland and rangeland easement programs currently have broad support among wildlife, ranching and other conservation interests as part of the conservation title of the farm bill. This is a liberal alternative focused on achieving environmental goals.

Effectiveness in conservation: The environmental benefits of easements are highest compared to all other options because the land is left undisturbed for several consecutive years. Easements rank the highest for protecting wildlife and habitat because the land is required to be managed solely for conservation and wildlife benefits. Wildlife benefits take years to accrue on land left idle, and these long-term easements provide the necessary amount of time for such benefits to develop.

Effectiveness in increasing income: The flexibility of the program would provide a moderate amount of income. Farmers nearing retirement age see this as a favorable option because it provides an income without having to actively farm the land. Possible tax advantages 


\section{AGRICULTURE AT A CROSSROADS}

provide other sources of income; owners may qualify for a charitable deduction for federal and state income taxes or may reduce their federal inheritance and estate taxes.

Links between income and conservation: The link between income and conservation is strong but as with $C R P$, acreage and funding is capped so farmers may get turned away from the program. Easements received a medium to high rank for this criterion because everyone who applies may not be accepted.

Feasibility: Political feasibility for easements is low because easements are the most restrictive land use option. An easement program has support among some wildlife, ranching, and other conservation interests. Inclusion of other environmentally sensitive areas would provide for a broader base of support. The requirements prescribed by the program, however, lose the support of some producer and agribusiness groups that oppose taking land out of production because of the resulting loss of agricultural business in the local economy. Instead, these groups prefer to leave land in production so that local businesses dependent on agricultural production can receive greater economic support from the farming community.

Administrative feasibility for easements is high because a low level of new bureaucracy would be required. This program would also serve as a complement to any other new or existing conservation program.

\section{Conservation Security Program Is the Best Option}

Based on this analysis, CSP appears to be the best option for supporting conservation and farmer income in the farm bill. CSP meets the needs of current agricultural policy, especially ensuring conservation. CSP is a compromise approach that focuses on conservation on productive agriculture lands.

Effectiveness in conservation: CSP scores a medium for both water and soil conservation and wildlife habitat. CRP and conservation easements have higher estimated environmental benefits but they do not seem to be politically feasible alternatives as stand-alone items. Cumulative benefits are expected from the unlimited number of farmers that can enroll in CSP. The resulting environmental benefits will rival other conservation programs with enrollment limitations. Because land enrolled in CSP can remain in production, many more farmers will be eligible for CSP than for programs that require the land to be taken out of production.

Effectiveness in increasing income: CSP scores high for supporting farmer income. Because land in CSP stays in agricultural production, many farmers will be eligible and will therefore benefit from the income support. Flex Fallow scored the same on this criterion but it has fewer environmental benefits and therefore is not recommended.

Strength of conservation requirements: CSP scores high on the strength of the link between income payments and conservation practices. Conservation easements also scored well but easements are not considered politically feasible.

Feasibility: CSP ranks high for political feasibility. Because of the close split between political parties in Congress, the political climate is moderate. As a result, the majority of support is coalescing around CSP. One challenge is that CSP will most likely create a new level of bureaucracy but this is a surmountable problem.

Some organizations may not be satisfied with the compromise approach adopted by CSP. In particular, some environmental groups may be concerned that this program does not meet their goals for environmental protection. Supporting feasible policies is the best option for the environment. CSP does not rank the highest on the conservation criteria but of the feasible policies it scores highest for conservation goals.

\section{Successful Implementation and Evaluation of the New Policy}

USDA must be funded and staffed adequately to accomplish the goals and objectives of any new or existing conservation programs. Qualified personnel are necessary to deliver the programs and funding must be ensured for the conservation programs to succeed.

If CSP were implemented, agencies should establish evaluation protocols to monitor conservation practices and programmatic goals. In the past, money has not been appropriated and allocated to the extent needed to perform effective program swaluation for many conservation programs. 


\section{Moving Down the New Path}

Environmental concerns and the long-term integrity of the nation's cropland make conservation a priority for the farm bill. Likewise, concern over inadequate farm. income necessitates an approach to programs that will support a sustainable source of income. These two concerns are not mutually exclusive. In fact, conservation and sustainable income can be highly complementary. Options exist for providing adequate income for farmers by requiring them to practice environmentally beneficial agriculture techniques.

CSP in particular appears to effectively blend conservation and income support by focusing upon conservation on productive agriculture lands. Conservation on working lands is an approach that Congress has funded less than conservation for lands in retirement.

In the future, a combination approach that capitalizes on the desired elements of several different programs may be preferable; in the end it may take more than one program to achieve the desired conservation and income results. Income-focused programs like Flex Fallow could be combined with environmental programs such as conservation easements and CRP into a larger bill based on a program like CSP. These types of programs are all compatible and complementary.

The political future will always be uncertain; this uncertainty is not unique to this policy analysis. In light of this uncertainty, many feasible options exist for securing income and conservation in a farm bill. The Conservation Security Program is one of these policies that would provide a compromise approach. Ultimately, CSP would complement several other programs that together could comprise a comprehensive farm bill conservation title.

\section{References}

Bardach, Eugene. (2000). A practical guide for policy analysis. New York: Chatham House Publishers.

Commission on $21^{\text {st }}$ Century Production Agriculture. The status of U.S. agriculture. Washington, D.C. 1998, December.

Committee on Agriculture, Nutrition and Forestry. U.S. Senate. Agriculture, conservation and rural enhancement act of 2001: Report to accompany S.
1731. $107^{\text {th }}$ Congress, $1^{\text {st }}$ Session. 2001, December 7.

Congressional Research Service. Report 97-905: Agriculture: A glossary of terms, programs, and laws. Jasper Womach. 1997, October 1.

Congressional Research Service. Report 97-673: Conservation reserve program: Status and current issues. Jeffrey Zinn,. 2000, May 23.

Congressional Research Service. Report IB10043: Farm economic relief: Issues and options for congress. Jasper Womach and Geoffrey S. Becker. 2000, Oct. 13.

Congressional Research Service. What is a farm bill? Jean Yavis Jones, Charles Hanrahan and Jasper Womach. 2001, May 5.

Doering, Otto. (2000, July 8). The politics of the farm bill: The reality factor. www.fb-net.org/FB/ workshop/OttoDoering.htm. 2000, October 16.

Economic Research Service (ERS). U.S. Department of Agriculture. Farm Income Reports. 1998, December.

Environmental Protection Agency. National waterquality inventory: 1998 report to congress. 2000, June.

Farm Service Agency. The conservation reserve program. U.S. Department of Agriculture. 1999, June.

Farm Service Agency. (No date). The conservation reserve program. 1997. www.fsa.usda.gov/dafp/ cepd $/ 12 \mathrm{crplogo} /$ page24.htm. 2000, November 5 .

Farm Service Agency. (No date). U.S. Department of Agriculture. www.fsa.usda.gov/dafp/cepd/ 12 crplogo/history.htm. 2000, November 5.

Food and Agricultural Policy Research Institute (FAPRI). FAPRI analysis of the flexible fallow program: FAPRI-UMC report \#13-99. 1999, August.

Hohman, William. (No date). Farm bill contributions to wildlife conservation. www.fb-net.org/FB/ ContribToWildlife.htm. 2000, December 9.

Johnson, Tim. U.S. Senate. Flexible fallow fact sheet. 2000, Fall. 


\section{AGRICULTURE AT A CROSSROADS}

Natural Resources Conservation Service (NRCS). 1997 State of the land update. 1998, September.

U.S. Department of Agriculture. (No date). www.fsa.usda.gov/pas/news/releases/1999/10/ 0391.htm. 2000, December 10.

U.S. Department of Agriculture. Food and agricultural policy: Taking stock for the new century. 2001, September.

U.S. Department of Agriculture - National Agricultural Statistics Service. 1997 Census of Agriculture. 1997.

Uri, Noel D. (No date). 1997 State of the land update. [Online]. Resources Inventory Division, Natural Resources Conservation Service. www.swcs.org/ t publicaffairs uri.htm. 2001, July 31 .

Wildlife Management Institute, et al. Planting the seeds for conservation in America: The farm bill conservation programs' needs and successes. 2002 January. 